\title{
The Percutaneous Endoscopic Lumbar Interbody Fusion (PELIF): An Advanced and Innovation Technique
}

\author{
${ }^{1}$ Department of Spine Surgery, Potiguar University, Natal, \\ Rio Grande do Norte, Brazil \\ 2Department of Pediatric Orthopedics, Potiguar University, Natal, \\ Rio Grande do Norte, Brazil \\ ${ }^{3}$ Department of Pediatric Orthopedics, Institute of Medical Assistance to \\ the State Public Servant (lamspe) Advisor, Sao Paulo, Sao Paulo, Brazil \\ Int J Recent Surg Med Sci 2019;5:31-34
}

Anibal Correia Silva ${ }^{1}$ Tabata de Alcantara ${ }^{2}$ Monica Paschoal Nogueira ${ }^{3}$

\begin{abstract}
Address for correspondence Anibal Correia Silva, MD, Department of Spine Surgery, Potiguar University, Avenida Engenheiro Roberto Frerire, 2184 Capim Macio, Natal, RN 59082-902, Brazil (e-mail: anibalcoluna@yahoo.com.br).
\end{abstract}
Abstract
Keywords
- endoscopic
- fusion
- spine

The degenerative spine changes, and its costs, have increased with high rates of work absenteeism and difficult clinical management. The search for minimally invasive treatments, with better results and early patients recover, with rapid hospital discharge are alternatives for these problems. The percutaneous endoscopic lumbar interbody fusion (PELIF) is a new and advanced option.

\section{Introduction}

Lumbar pain is an important cause of incapacitation for work, reaching at $90 \%$ of the population, ${ }^{1}$ with an alarming rate of absenteeism. ${ }^{2}$ Its treatment is difficult with ineffective responses to the clinical treatment. ${ }^{3}$ Modern surgical alternatives have provided better results and healing potential. ${ }^{4}$ The search for alternative treatments, with lower cost and faster patients'return to their work activities, has increased too. ${ }^{5}$ The authors report an advanced and innovative technique of endoscopic fusion in response to these problems.

\section{Case Report}

The patient is a 36-year-old male with left lombociatalgia for 2 years. He was treated with physical therapy, nonsteroidal anti-inflammatory drugs (NSAIDs), and bed rest without any improvement. Physical examination showed Laségue's signs on the left foot, positive Valsalva's maneuver, dorsiflexion grade IV, and hypoesthesia in the anterior aspect of the left foot. The magnetic resonance imaging (MRI) showed extruded left foraminal disc herniation at L4 and L5, associated with segmental instability at L3 and L4 and L4 and L5, as a result of interspinal lesions and facet joint subdislocation. The patient, with no clinical improvement after 2 years of nonsurgical treatment, agreed with surgical treatment by foraminal disc decompression at L4 and L5 and percutaneous endoscopic lumbar interbody fusion (PELIF) at L3 and L5.

\section{Surgical Technique}

The computed tomography and MRI showed the interest area and the entry point distance to be puncture. This avoids unnecessary resections or neural tissue manipulations (-Fig. 1).

With the use of the image enhancer, the puncture was performed with an $18 \mathrm{G}$ needle in the patient under general anesthesia. The intervertebral disc was accessed through the transforaminal route, followed by discography with iodinated contrast and methylene blue. A guide wire was positioned through the needle, sliding it to the center of the disc ( - Fig. 2). Successive dilators were placed on the guidewire and a beveled working cannula (7.1 $\mathrm{mm}$ of inner diameter) was placed on the dilators, which were then removed ( - Fig. 3 ), and the endoscope (6.9 $\mathrm{mm}$ of outer diameter, $6.1 \mathrm{~mm}$ of working channel, and 20-degree view angle) was inserted. The endoscope permits direct discal lesion visualization and the surrounding neural structures; It approaches and ressects just the necessary, without neural manipulations and avoiding instability or postoperative fibrosis.

Initially, the surgeon conducted the endoscopic visualization to the facet's superior articular process (SAP), with endoscopic partial facetectomy, using an endoscopic drill $\operatorname{system}^{6}(-$ Fig. 4). This enabled a decompression of the neural foramen, under direct visualization of neural structures, and provided us the sufficient space for more safe and simple surgical procedures. So, a new guidewire is then
DOI https://doi.org/

$10.1055 / \mathrm{s}-0039-1692730$ ISSN 2455-7420.
License terms

()(1) $\ominus \circledast$ 


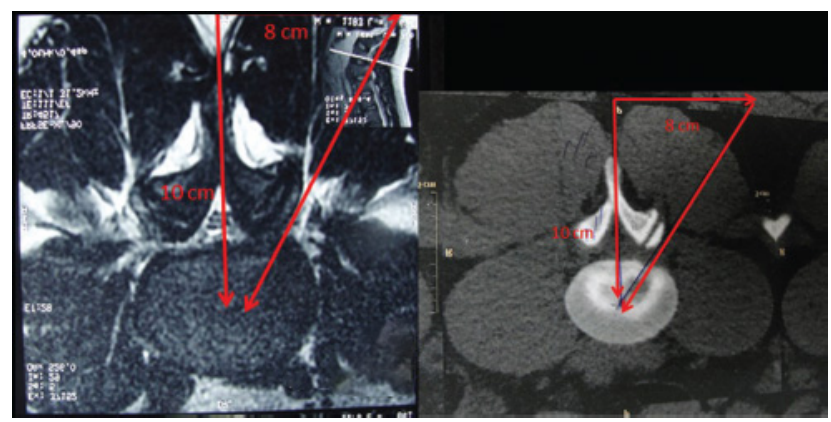

Fig.1 The computed tomography and magnetic resonance imaging show the entry point distance to be puncture..

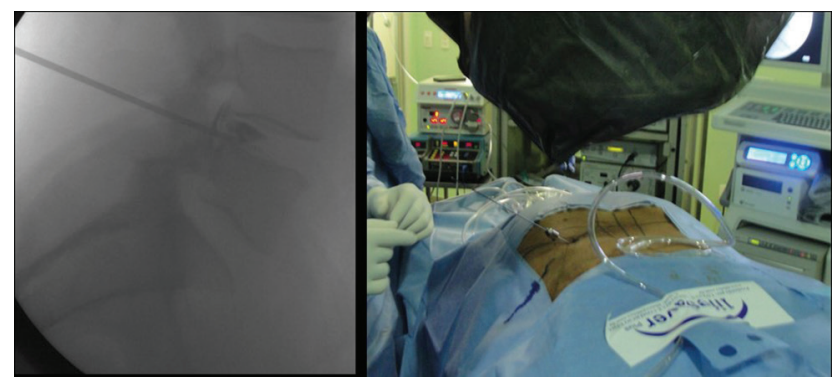

Fig. 2 Discography of the disc space and placement of guide wire.

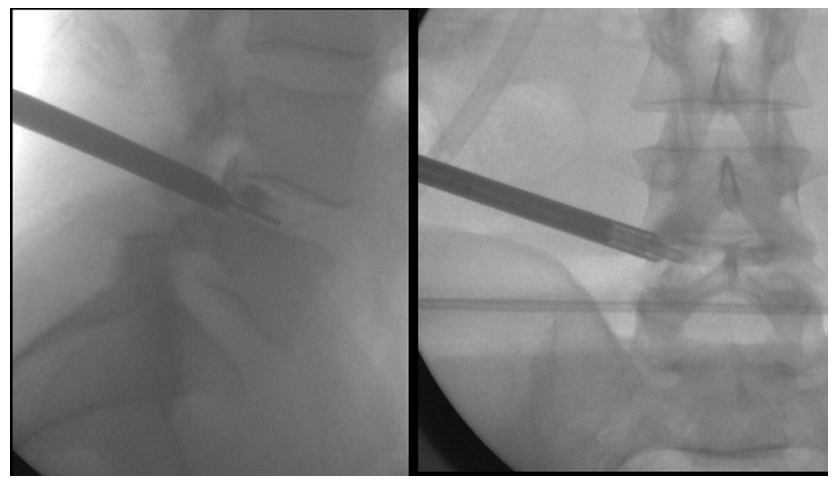

Fig. 3 Successive dilators are placed on the guide wire and the endoscope is inserted.

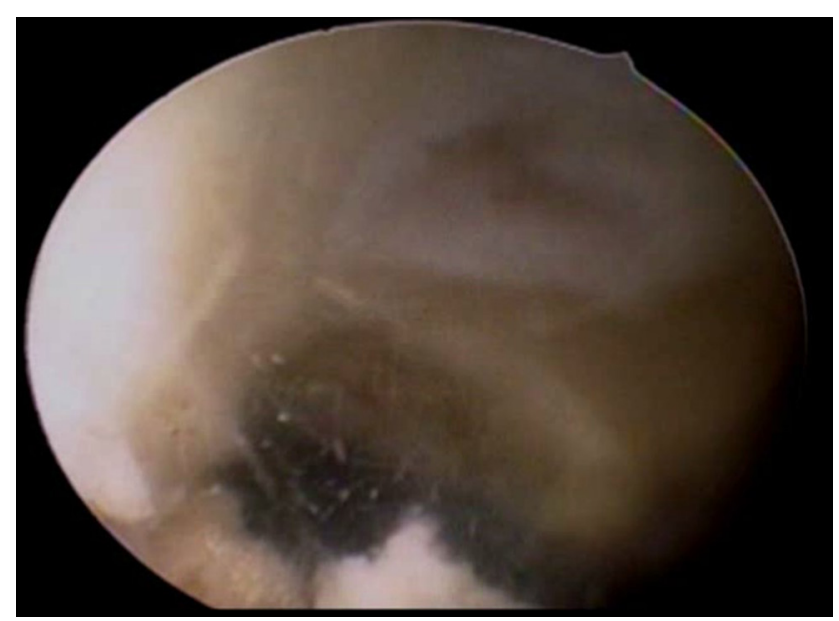

Fig. 4 The endoscopic visualization to the facet's superior articular process, with endoscopic partial facetectomy. inserted through the working channel of the endoscope, being positioned in the center of the disc space. The endoscope was then withdrawn, with the certainty that no neural structure was interposed or close to the working cannula, and successive tubular dilators were passed over the guide wire in a total of four, with the latter having a working channel of $15.0 \mathrm{~mm}$ (inner diameter; - Fig. 5) that allowed the reaming disc space and endplate preparation under fluoroscopic and endoscopic guidance. After this, the polyetheretherketone (PEEK) transforaminal lumbar intersomatic fusion (TLIF) CAGEs (8-10 mm of height) was inserted ( - Fig. 6), without risk to the neural structures. The two CAGEs were placed under fluoroscopic and endoscopic guidance, positioned parallel, and in the anterior third of the intersomatic space for better mechanical support ( - Fig. 7). The endoscope is reintroduced through the $15 \mathrm{~mm}$ cannula for direct final visualization of the CAGES and bone graft in the intersomatic space ( - Fig. 8).

The spinal fixation was followed by the use of a percutaneous pedicular screw system ${ }^{6}$ (-Fig. 9). This appropriately sized 6 or $7 \mathrm{~mm}$ in diameter pedicle screws were then inserted and bilateral connecting rods were passed subfascially; following final tightening of the set screws, the rod and screw extenders were removed. After all instruments were removed, direct closure of the skin was done. No drainage was required. The patient was discharged after 2 days.

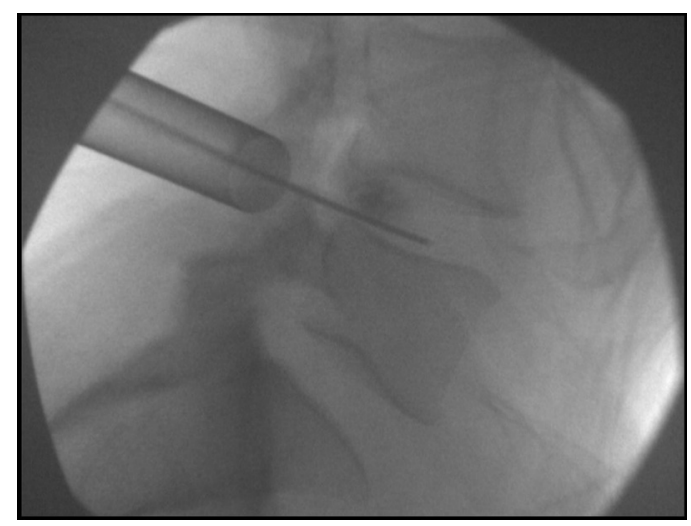

Fig. 5 The latter tubular dilators of $15.0 \mathrm{~mm}$ (inner diameter).

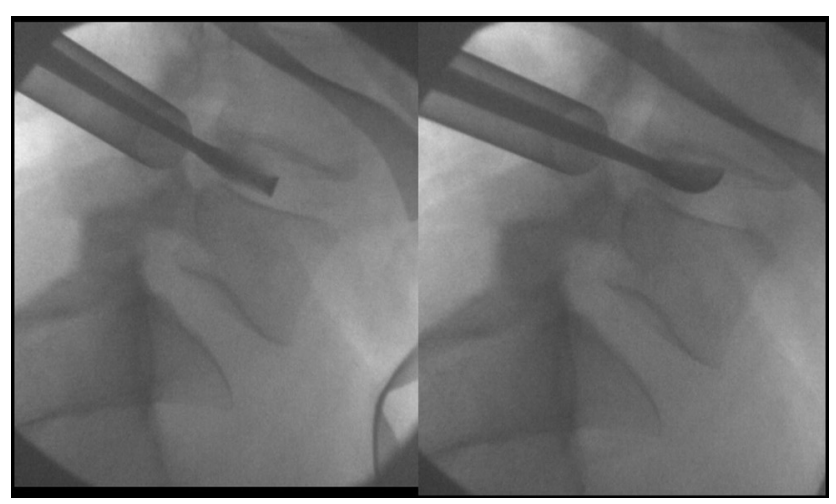

Fig. 6 The remaining disc space and endplate preparation. 


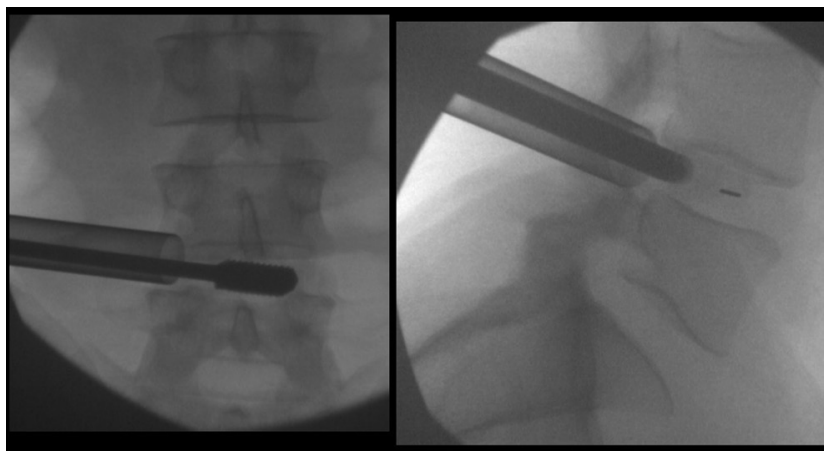

Fig. 7 The two CAGEs are placed under fluoroscopic and endoscopic guidance.

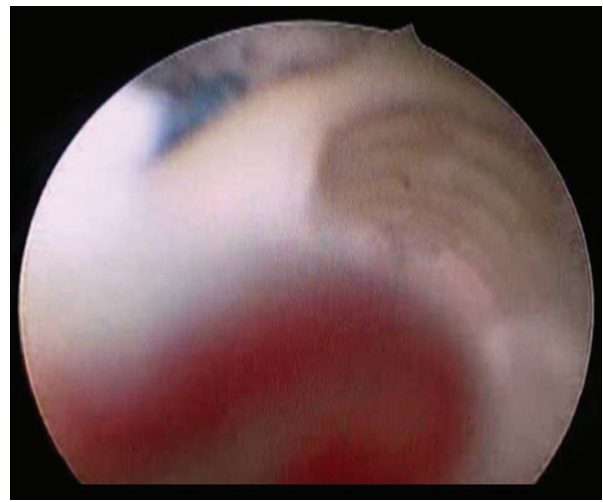

Fig. 8 The final endoscope visualization of the CAGES in the intersomatic space.

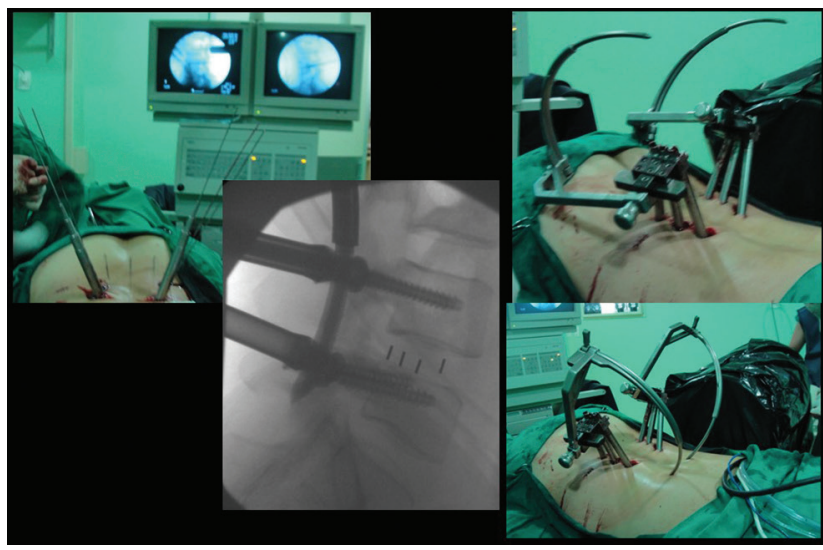

Fig. 9 The spinal fixation with the use of a percutaneous pedicular screw system.

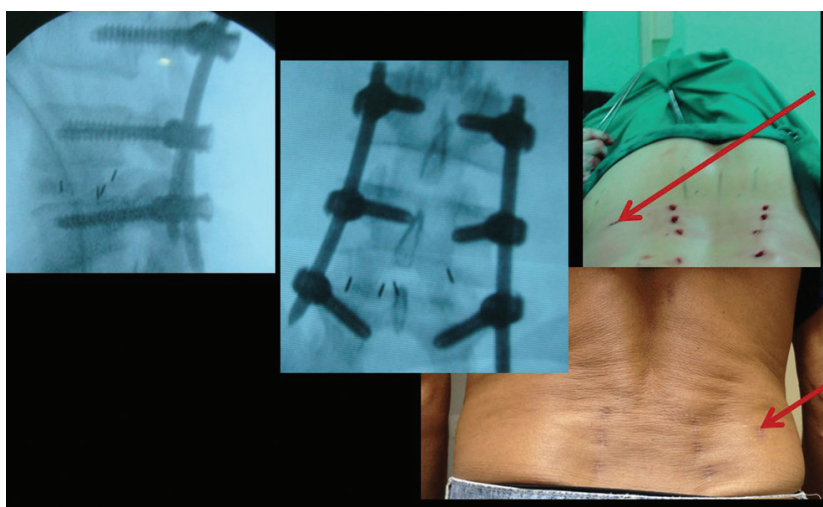

Fig. 10 The final excellent cosmetic-functional result.

\section{Discussion}

The percutaneous TLIF (pTLIF), which can be performed with an incision of only $1.5 \mathrm{~cm}$, leading to a hospital discharge with only 24 hours of patient hospitalization was proposed by Morgenstern in 2010. ${ }^{7}$ He reviewed his results in 2013 and $2015,,^{8,9}$ concluding that the technique has the same efficacy and safety of open lumbar arthrodesis, with a faster and more regular recovery of the patients than in the conventional method, the bone structure and the surrounding soft parts being even less aggressive.

Lee $^{10}$ also showed that the advantages of the percutaneous technique are small diameter incisions, with no-bone or soft-tissue lesions, the facet joint is not resected, stability is not compromised, there is no manipulation of neural structures, fistula, or neurological impairments, bleeding is negligible and has a low risk of infection. We used the PEEK TLIF intersomatic CAGE to restore the disc height. However, Krishnan ${ }^{11}$ has showed that the cost of instrumented expandable cage may make it nonfeasible, and the percutaneous transforaminal endoscopic decompression and cageless percutaneous bonegraft, with a good endplate preparation, have greater fusion rates.

\section{Conclusion}

The treatment of degenerative disc diseases is still controversial and much has to be advanced; however, the combination of endoscopic decompression techniques, associated with percutaneous pedicle screw fixation, has shown an excellent

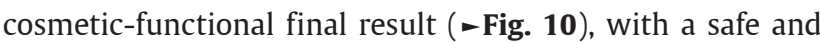
effective option to neural decompress interbody fusion. The PELIF is a new and advanced option to effective interbody fusion in full endoscopic view without technical limitations.

\section{Conflict of Interest}

None declared.

\section{References}

1 Chou LH, Lew HL, Coelho PC, Slipman CW. Intradiscal electrothermal annuloplasty. Am J Phys Med Rehabil 2005;84(7):538-549

2 Webster BS, Verma S, Pransky GS. Outcomes of workers compensation claimants with low back pain undergoing intradiscal electrothermal therapy. Spine 2004;29(4):435-441

3 Bhagia SM, Slipman CW, Nirschl M, et al. Side effects and complications after percutaneous disc decompression using coblation technology. Am J Phys Med Rehabil 2006;85(1):6-13

4 Chen YC, Lee SH, Chen D. Intradiscal pressure study of percutaneous disc decompression with nucleoplasty in human cadavers. Spine 2003;28(7):661-665

5 Bono CM, Iki K, Jalota A, Dawson K, Garfin SR. Temperatures within the lumbar disc and endplates during intradiscal electrothermal therapy: formulation of a predictive temperature map in relation to distance from the catheter. Spine 2004;29(10):1124-1129,discussion1130-1131

6 Kim HS, Park KH, Ju CI, Kim SW, Lee SM, Shin H. Minimally invasive multi-level posterior lumbar interbody fusion using a percutaneously inserted spinal fixation system: technical tips, surgical outcomes. J Korean Neurosurg Soc 2011;50(5):441-445 
7 Morgenstern R. Full endoscopic transforaminal lumbar interbody fusion approach with percutaneous posterior transpedicular screw fixation in a case of spondylolisthesis grade I with L4-5 central stenosis correspondence. J Crit Spine Cases 2010;(3):115-119

8 Morgenstern R, Morgenstern C. Endoscopically assisted transforaminal percutaneous lumbar interbody fusion. In: Lewandrowski KU, Lee SH, Iprenburg M, eds. Endoscopic Spinal Surgery. London: JP Medical Publishers;2013:129-134

9 Morgenstern R, Morgenstern C. Percutaneous transforaminal lumbar ilnterbody fusion (pTLIF) with a posterolateral approach for the treatment of denegerative disk disease: feasibility and preliminary results. Int J Spine Surg 2015; 9(9):41

10 Lee SH. Percutaneous transforaminal lumbar interbody stabilization. In: Kim DH, Kim KH, Kim YC, eds. Minimally Invasive Percutaneous Spinal Techniques. Philadelphia, PA: Elsevier Saunders;2011:367-73

11 Krishnan A, Barot MP, Dave BR, et al. Percutaneous transforaminal endoscopic decompression and cageless percutaneous bone graft transforaminal lumbar interbody fusion: a feasibility study. J Orthopaedics Allied Sciences 2018;6(3):21-27 